\title{
Dehydrogenase/reductase SDR family member 2 silencing sensitizes an oxaliplatin-resistant cell line to oxaliplatin by inhibiting excision repair cross-complementing group 1 protein expression
}

\author{
JI-MIN LI ${ }^{1}$, GUAN-MIN JIANG ${ }^{2}$, LIANG ZHAO ${ }^{1}$, FANG YANG ${ }^{1}$, WEI-QI YUAN ${ }^{1}$, HAO WANG ${ }^{1}$ and YI-QIN LUO $^{1}$ \\ ${ }^{1}$ Department of Laboratory Medicine, The Affiliated Anhui Provincial Hospital of Anhui Medical University, \\ Hefei, Anhui 230000; ${ }^{2}$ Department of Clinical Laboratory, The Fifth Affiliated Hospital, \\ Sun Yat-Sen University, Zhuhai, Guangdong 510140, P.R. China
}

Received March 29, 2019; Accepted July 26, 2019

DOI: $10.3892 /$ or.2019.7291

\begin{abstract}
Oxaliplatin (Oxa)-based chemotherapy is widely used as the first-line treatment for colorectal cancer (CRC). However, Oxa-resistance is common for many postoperative CRC patients. To explore drug resistance in $\mathrm{CRC}$, an Oxa-resistant cell line, HCT116/Oxa, was established from parental HCT116 cells. These Oxa-resistant cells exhibited characteristics of epithelial-mesenchymal transition (EMT) and a higher migratory capacity than parental cells. Protein profiles of HCT116/Oxa and HCT116 cells were compared using a tandem mass tag-based quantitative proteomics technique. The protein dehydrogenase/reductase SDR family member 2 (DHRS2) was revealed to be highly expressed in HCT116/Oxa cells. Silencing of DHRS2 in HCT116/Oxa cells effectively restored Oxa-sensitivity by suppressing the expression of excision repair cross-complementing group 1 protein via a p53-dependent pathway, and reversed the EMT phenotype. Overall, the suppression of DHRS2 expression may be a promising strategy for the prevention of Oxa-resistance in CRC.
\end{abstract}

\section{Introduction}

Colorectal cancer (CRC) is a leading cause of morbidity and mortality worldwide (1). The most common treatment options for CRC are surgery and chemotherapy, with the third-generation platinum drug Oxaliplatin (Oxa) being a chief therapeutic

Correspondence to: Professor Yi-Qin Luo or Dr Hao Wang, Department of Laboratory Medicine, The Affiliated Anhui Provincial Hospital of Anhui Medical University, 17 Lujiang Road, Hefei, Anhui 230000, P.R. China

E-mail: luoyiqin2004@hotmail.com

E-mail: wanghao986118@163.com

Key words: colorectal cancer, oxaliplatin, DHRS2, p53, ERCC1 strategy (2). However, reports of Oxa-resistance in CRC therapy are gradually increasing, and this acquired resistance has become a major obstacle to patient survival in CRC (3).

Epithelial-mesenchymal transition (EMT) is an essential phenotypic conversion in embryonic development, tissue remodeling, wound healing, tumor invasion and metastasis. As a dynamic and reversible process, EMT often occurs at the invasive front of many metastatic cancers. The loss of E-cadherin is considered as a vital event in the EMT process (4). Emerging evidence suggests that EMT plays an important role in acquisition of chemotherapy resistance in various cancer cells (5). Excision repair cross-complementing group 1 protein (ERCC1) plays a key role in nucleotide excision repair and in removing platinum-induced DNA adducts (6). Previous studies have revealed that ERCC1 expression is negatively correlated to E-cadherin in lung cancer (7). Furthermore, overexpression of snail, ZEB1/2, EMT-related transcription factors, can contribute to chemoresistance by promoting ERCC1 expression in head and neck squamous cell carcinoma cells and lung cancer cells $(8,9)$. In addition, there are some studies indicating that $\mathrm{p} 53$ can promote collective cellular migration by inducing EMT (10).

Dehydrogenase/reductase SDR family member 2 (DHRS2) was first identified as a nuclear protein in the sodium butyrate-treated human hepatoblastoma cell line HepG2 (11). DHRS2 belongs to the short-chain dehydrogenase/reductase (SDR) family of enzymes that are present in all life forms and are mainly NAD/NADP-dependent oxido-reductases that are active on a large and heterogeneous set of substrates including steroids, retinoids, prostaglandins, metabolites, and xenobiotics $(12,13)$. DHRS2 maps to chromosome $14 \mathrm{q} 11.2$, which is a region characterized by high-frequency loss of heterozygosis in many different tumors (14-16), and high levels of DHRS2 indicate a possible function in tumorigenesis (17). In fact, DHRS2 has been revealed to be highly concentrated in several types of cancer cells and could be a prognostic marker of prostate cancer (18), bladder carcinomas (19), and sporadic breast cancer (20). DHRS2 is also aberrantly expressed in esophageal squamous cell carcinoma (ESCC) where its overexpression enhanced 
cancer cell aggressiveness (21). Further characterization of DHRS2 revealed that its aberrant expression was associated with the mechanisms of drug resistance in acute myelogenous leukemia and gastric carcinogenesis $(22,23)$. However, it is not known whether there is an underlying relationship between DHRS2 and chemotherapy resistance in CRC.

In the present study, proteomics was used to compare protein expression profiles between the parental colon cancer cell line HCT116 and the Oxa-resistant subline HCT116/Oxa cells. Notably, it was revealed that DHRS2 protein levels were significantly upregulated in HCT116/Oxa cells compared with parental cells. Furthermore, silencing of DHRS2 sensitized HCT116/Oxa cells to Oxa by downregulating ERCC1 through a p53-dependent pathway, and reversed EMT. This finding revealed that DHRS2 could act as an important regulator of Oxa-resistance associated with EMT in CRC, which may suggest novel strategies for defeating Oxa-resistance.

\section{Materials and methods}

Antibodies and reagents. Primary antibodies against ABCB1 (cat. no. 13342), PARP (cat. no. 9532) and LC3-I/II (cat. no. 12741) were obtained from Cell Signaling Technology, Inc. Primary antibodies against ABCC1 (cat. no. ab24102), ABCC2 (cat. no. ab203397), and ABCG2 (cat. no. ab24115) were obtained from Abcam. Primary antibodies against E-cadherin (cat. no. 20874-1-AP), vimentin (cat. no. 60330-1-Ig), Bcl-2 (cat. no. 12789-1-AP), p53 (cat. no. 10442-1-AP), ERCC1 (cat. no. 14586-1-AP), CA9 (cat. no. 11071-1-AP), DHRS2 (cat. no. 15735-1-AP), GAPDH (cat. no. 60004-1-Ig) and $\beta$-actin (cat. no. 60008-1-Ig) were obtained from Proteintech Group. The PrimeScripts RT reagent kit and SYBRs Premix Ex Taq ${ }^{\mathrm{TM}}$ were obtained from Takara (Takara Biotechnology Co., Ltd.).

Cell culture and the establishment of an Oxa-resistant cell line. The HCT116 colorectal carcinoma cell line was obtained from the Type Culture Collection of the Chinese Academy of Sciences. HCT116 cells were maintained in Dulbecco's modified Eagle's medium (DMEM)/F12 culture medium (Gibco-BRL; Thermo Fisher Scientific, Inc.) containing $10 \%$ fetal bovine serum (FBS), $100 \mathrm{U} / \mathrm{ml}$ penicillin, and $100 \mathrm{mg} / \mathrm{ml}$ streptomycin. The Oxa-resistant CRC cell line HCT116/Oxa was established in our laboratory. Briefly, HCT116 cells were exposed to a series of stepwise-increased concentrations of Oxa to develop an HCT116/Oxa-resistant cell line. Both cell lines were cultured in a $5 \% \mathrm{CO}_{2}$ atmosphere at $37^{\circ} \mathrm{C}$.

Proteomic sample preparation. Cells were sonicated three times on ice using a high intensity ultrasonic processor (Ningbo Scientz Biotechnology Co., Ltd.) in lysis buffer $(8 \mathrm{M}$ urea, $1 \%$ protease inhibitor cocktail). After $12,000 \mathrm{x}$ g at $4^{\circ} \mathrm{C}$ for $10 \mathrm{~min}$, protein concentration was determined with a $\mathrm{BCA}$ kit (Beyotime Institute of Biotechnology) according to the manufacturer's instructions. For digestion, the protein solution was reduced with $5 \mathrm{mM}$ dithiothreitol at $56^{\circ} \mathrm{C}$ for $30 \mathrm{~min}$ and alkylated with $11 \mathrm{mM}$ iodoacetamide for $15 \mathrm{~min}$ at room temperature in darkness. Triethylammonium bicarbonate buffer (TEAB) was added to dilute samples. Finally, trypsin was added at a 1:50 trypsin: Protein mass ratio for the first digestion overnight and a 1:100 ratio for a second 4 h-digestion.
Subsequently, peptides were then desalted by a Strata X C18 SPE column (Phenomenex), vacuum-dried, dissolved in $0.5 \mathrm{M}$ TEAB, and labeled based on the tandem mass tag (TMT) kit. Briefly, $1 \mathrm{U}$ of TMT reagent was dissolved in acetonitrile and added to peptides for incubation for $2 \mathrm{~h}$ at room temperature, followed by pooling, desalting, and drying by vacuum centrifugation. Agilent 300Extend C18 column ( $5 \mu \mathrm{m}$ particles, $4.6 \mathrm{~mm}$ ID, $250 \mathrm{~mm}$ length) was used to fractionate peptides. Briefly, peptides were first separated with a gradient of 8 to $32 \%$ acetonitrile ( $\mathrm{pH} 9.0$ ) over $60 \mathrm{~min}$ into 60 fractions. Then, they were combined into 18 fractions and subjected to vacuum-drying.

Liquid chromatography-tandem mass spectrometry. The peptides were dissolved in $0.1 \%$ formic acid (solvent $\mathrm{A}$ ), and separated using EASY-nLC 1000 ultra-performance liquid chromatography UPLC (Thermo Fisher Scientific, Inc.). The gradient was an increase from 6 to $23 \%$ solvent $\mathrm{B}(0.1 \%$ formic acid in $98 \%$ acetonitrile) over $26 \mathrm{~min}, 23-35 \%$ in $8 \mathrm{~min}$, climbing to $80 \%$ in $3 \mathrm{~min}$, and holding at $80 \%$ for the last $3 \mathrm{~min}$ at a constant flow rate of $400 \mathrm{nl} / \mathrm{min}$.

The peptides were subjected to a nano electrospray ionization source followed by tandem mass spectrometry (MS/MS) in Q Exactive ${ }^{\mathrm{TM}}$ Plus (Thermo Fisher Scientific, Inc.) coupled online to the UPLC. The MS scan was set as $350-1,800 \mathrm{~m} / \mathrm{z}$ and 70,000 resolution; the MS/MS scan was set as $100 \mathrm{~m} / \mathrm{z}$ and 17,500 resolution. The automatic gain control was set at $5 \mathrm{E} 4$, and the data-dependent acquisition procedure was applied to data acquisition.

Data analysis. The resulting MS/MS data were processed using the Maxquant search engine (v.1.5.2.8). Searches were performed against SwissProt human database (20,130 sequences) and reverse decoy database. Trypsin/P was specified as a cleavage enzyme allowing up to two missing cleavages. For precursor ions, the mass tolerances of the first search and main search were 20 and 5 ppm, respectively. The mass tolerance of fragment ions was $0.02 \mathrm{Da}$. The false discovery rate was adjusted to $<1 \%$ and the minimum score for peptides was set as $>40$.

MS analysis of TMT-labeled samples was performed on Q Exactive Protein intensities resulting from average single TMT reporter ion intensities obtained for each peptide associated with a specific protein. The average ratio of differential TMT 127/126 expression (1.5-fold increase or decrease) represents the ratio of two samples. Specifically, differentially expressed proteins were identified in our TMT experiment using 1.5 and 0.67 as upregulation and downregulation cutoff points, respectively.

Bioinformatics analysis (gene ontology and pathway analysis). Gene Ontology (GO) annotation and enrichment analyses were performed using DAVID (the Database for Annotation, Visualization and Integrated Discovery). GO with a corrected $\mathrm{P}<0.05$ was considered to indicate a statistically significant difference. Additionally, the Kyoto Encyclopedia of Genes and Genomes (KEGG) database was used to identify enriched pathways by a two-tailed Fisher's exact test to assess the enrichment of differentially expressed proteins against all identified proteins. Pathways with a corrected $\mathrm{P}<0.05$ were considered significant. These pathways were classified into hierarchical categories according to the KEGG website. 
Oxaliplatin sensitivity assay. The viability of HCT116/Oxa cells and parental cell was measured by the CCK-8 assay (Dojindo Molecular Technologies, Inc.). Briefly, cells were seeded in 96-well plates at a density of $1.0 \times 10^{4}$ cells and treated with different concentrations of Oxa for $48 \mathrm{~h}$. Then $10 \mu \mathrm{l} \mathrm{CCK}-8$ reagent was added to each well and incubated at $37^{\circ} \mathrm{C}$ for another $1 \mathrm{~h}$. The absorbance was measured for each well at a wavelength of $450 \mathrm{~nm}$. All assays were performed in triplicate.

Cell migration experiment. The cell migration assay was performed using a Transwell system ( $8 \mu \mathrm{m}$; Corning Inc.) according to the manufacturer's protocol. Approximately $5 \times 10^{4}$ cells were re-suspended in serum-free medium in the top chamber of the insert, and the bottom chamber was filled with DMEM/F12 containing $10 \%$ FBS. After $24 \mathrm{~h}$ of incubation, the cells that had migrated to the lower side of the membrane were fixed with $4 \%$ paraformaldehyde and stained with $0.1 \%$ crystal violet for $20 \mathrm{~min}$ at room temperature. The images were captured using a fluorescence microscope (E1000M Eclipse; Nikon Corp., Tokyo, japan) and the migrated cells was counted.

RNA interference. The siRNA against human ERCC1, DHRS2, p53 and control siRNA were synthesized by Shanghai GenePharma Co., Ltd. The sequence of the control siRNA was: 5'-UUCUCCGAACGUGUCACGUTT-3'. The target sequences for ERCC1 siRNA were: siRNA1, 5'-GCC AAGCCCUUAUUCCGAUTT-3'; and siRNA2, 5'-GCG ACGUAAUUCCCGACUATT-3'. The target sequences for DHRS2 siRNA were: siRNA1, 5'-GCGUGGUUCCAGGAA UUAUTT-3'; and siRNA2, 5'-GCUGUCAUCCUGGUCUCU UTT-3'. The target sequences for p53 siRNA were: siRNA1, 5'-CCACCAUCCACUACAACUATT-3'; and siRNA2, 5'-CCA CUGGAUGGAGAAUAUUTT-3'. Cells (1x10\%/well) were seeded on a 6-well plate and cultured until the next day. They were then transfected with 100 pmol siRNA oligomer mixed with Lipofectamine 2000 reagent (Life Technologies; Thermo Fisher Scientific, Inc.) in serum-reduced medium according to the manufacturer's instructions. After $6 \mathrm{~h}$, the medium was changed to complete culture medium, and the cells were incubated at $37^{\circ} \mathrm{C}$ in a $\mathrm{CO}_{2}$ incubator for another $24-48 \mathrm{~h}$ before harvest.

Quantitative real-time PCR. Total RNA from cell lines was extracted using TRIzol reagent (Invitrogen; Thermo Fisher Scientific, Inc.) according to the manufacturer's guidelines. A total of $500 \mathrm{ng}$ RNA was converted into cDNA using the PrimeScript ${ }^{\mathrm{TM}}$ kit (Takara Bio, Inc.) under the following conditions: $37^{\circ} \mathrm{C}$ for $15 \mathrm{~min}, 85^{\circ} \mathrm{C}$ for $5 \mathrm{sec}$, and were held at $4^{\circ} \mathrm{C}$. Quantification of target genes and the reference gene (GAPDH) was studied in triplicate on the ABI-7500 system (Applied Biosystems, Inc.; Thermo Fisher Scientific, Inc.) using SYBR-Green fluorescent-based assay (Takara Bio Inc.). The reaction conditions were as follows: Pre-denaturation at $95^{\circ} \mathrm{C}$ for $30 \mathrm{sec}$, followed by 40 cycles at $95^{\circ} \mathrm{C}$ for $5 \mathrm{sec}$ and $60^{\circ} \mathrm{C}$ for $34 \mathrm{sec}$. The primers used were as follows: DHRS2 forward, 5'-TCACAGAAAGCC TAGCACAG-3' and reverse, 5'-TGAGACCATCACCAA GCG-3'; GAPDH forward, 5'-GCACCGTCAAGGCTG AGAAC-3' and reverse, 5'-TGGTGAAGACGCCAGTGG A-3'; ERCC1 forward, 5'-CTCAAGGAGCTGGCTAAGATG
T-3' and reverse, 5'-CATAGGCCTTGTAGGTCTCCAG-3'; vimentin forward, 5'-TGAGTACCGGAGACAGGTGCAG-3' and reverse, 5'-TAGCAGCTTCAACGGCAAAGTTC-3'; and E-cadherin forward, 5'-TACACTGCCCAGGAGCCAGA-3' and reverse, 5'-TGGCACCAGTGTCCGGATTA-3'. The quantification was based on $\Delta \Delta C$ q calculations (24) and was normalized to GAPDH as a loading control.

Immunofluorescence. Treated cells were washed with ice-cold phosphate-buffered saline (PBS), fixed with $4 \%$ paraformaldehyde for $20 \mathrm{~min}$, and permeabilized with $0.3 \%$ Triton X-100 for $10 \mathrm{~min}$. After blocking with $2 \%$ bovine serum albumin for $30 \mathrm{~min}$ at room temperature, cells were incubated with primary antibodies against $\mathrm{E}$-cadherin or vimentin $(1: 100$ dilution) at $4^{\circ} \mathrm{C}$ overnight. Slides were then washed three times with PBS and incubated with Alexa Fluor 488 (1:1,000 dilution; cat. no Ab150077) or Alexa Fluor 594-conjugated secondary antibodies (1:1,000 dilution; cat. no. ab150120; both Abcam) for $1 \mathrm{~h}$ at room temperature. Nuclei were stained with 4',6-diamidino-2-phenylindole $(10 \mu \mathrm{g} / \mathrm{ml})$ for $10 \mathrm{~min}$. Samples were examined to analyze the expression of E-cadherin and vimentin.

Western blotting. After washing three times with ice-cold PBS, cells were lysed by western blot lysis buffer containing $50 \mathrm{mM}$ Tris- $\mathrm{HCl}$ (pH 7.6), $150 \mathrm{mM} \mathrm{NaCl}, 1 \mathrm{mM}$ EDTA, 1\% NP-40, $0.5 \% \mathrm{Na}$-deoxycholate, $5 \mu \mathrm{g} / \mathrm{ml}$ aprotinin, $5 \mu \mathrm{g} / \mathrm{ml}$ leupeptin, and $1 \mathrm{mM}$ phenylmethylsulfonyl fluoride on ice. Lysates were centrifuged at $12,000 \mathrm{x} \mathrm{g}$ for $20 \mathrm{~min}$ at $4^{\circ} \mathrm{C}$ and denatured at $100^{\circ} \mathrm{C}$ for $10 \mathrm{~min}$. Equal amounts of protein samples (30 $\mu \mathrm{g} / \mathrm{sample}$ ) were loaded in each well of a $10 \%$ sodium dodecyl sulfate polyacrylamide gel, then electrophoretically transferred onto $0.45 \mu \mathrm{m}$ polyvinylidene difluoride membranes. Following blocking with $5 \%$ non-fat milk at room temperature for $2 \mathrm{~h}$, the membranes were incubated with primary antibodies (1:1,000 dilution) at $4^{\circ} \mathrm{C}$ overnight, then with horseradish peroxidase-conjugated goat anti-mouse IgG (1:5,000 dilution; cat. no. SA00001-1) or horseradish peroxidase-conjugated goat anti-rabbit IgG (1:5,000 dilution; cat. no. SA00001-2; both Wuhan Sanying Biotechnology) for $2 \mathrm{~h}$ at room temperature. Chemiluminescence reagent (Pierce; Thermo Fisher Scientific, Inc.) was used to detect specific immune complexes. Protein gray value detection was performed using ImageJ software (version 1.4.3.67; National Institutes of Health, Bethesda, MD, USA).

Statistical analysis. Results were expressed as the means \pm SD of three independent experiments unless otherwise specified. Data from two groups were compared using two-tailed unpaired Student's t-test. One-way analysis of variance (ANOVA) with Tukey's post hoc test was used to assess differences among groups. These analyses were performed using GraphPad Prism Software version 5.0 (GraphPad Software Inc.). $\mathrm{P}<0.05$ was considered to indicate a statistically significant difference.

\section{Results}

ERCC1 is overexpressed in HCT116/Oxa cells and contributes to their resistance to Oxa. As revealed in Fig. 1A, HCT116/Oxa cells revealed increased resistance to Oxa compared with their 

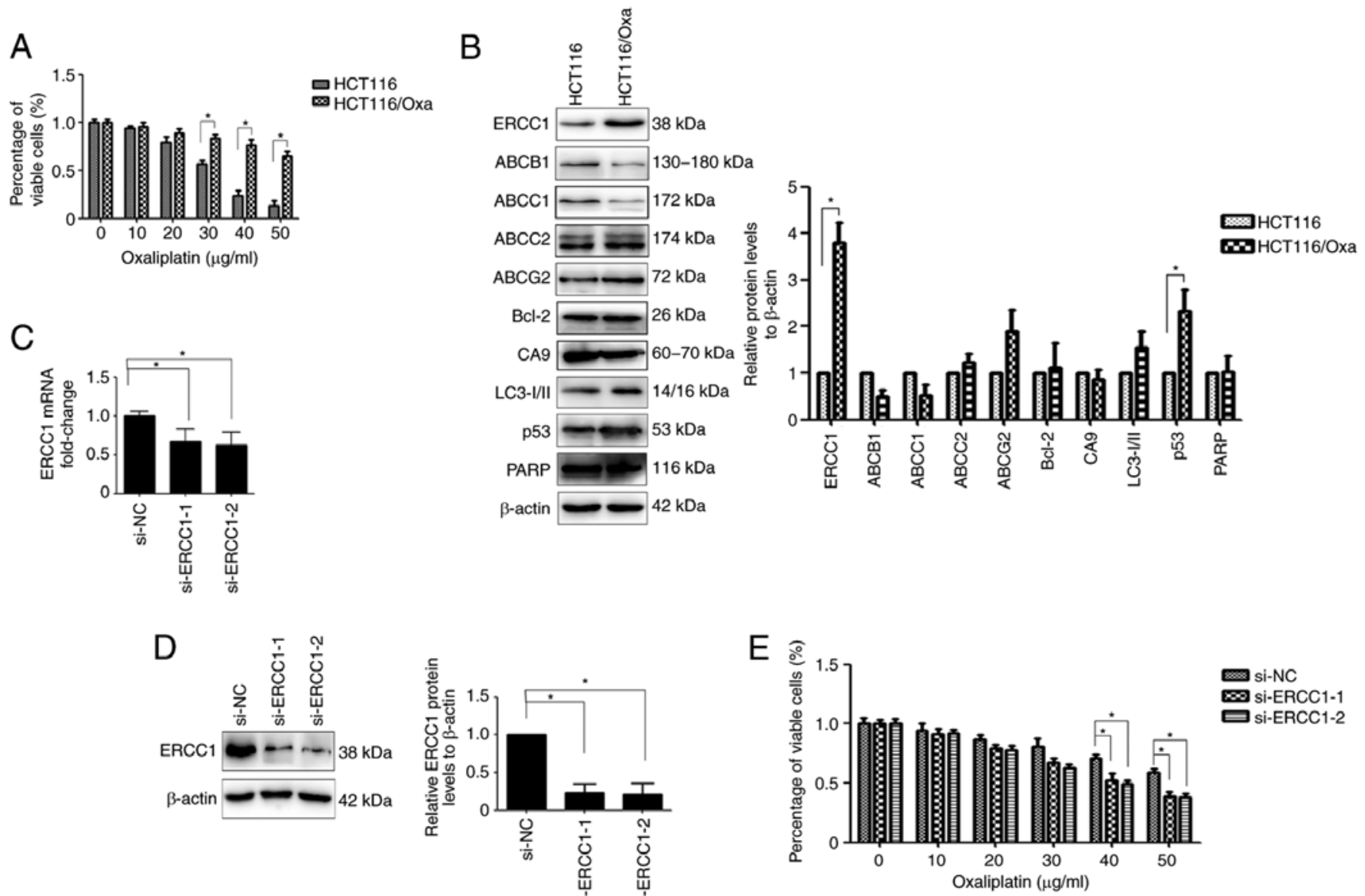

Figure 1. ERCC1 is overexpressed in HCT116/Oxa cells and contributes to Oxa resistance. (A) Viability of HCT116 and HCT116/Oxa cells after treatment with different concentrations of Oxa for $48 \mathrm{~h}$. (B) Expression of resistance-related proteins was evaluated by western blotting. (C and D) Expression analysis of ERCC1 in HCT116/Oxa cells infected with si-ERCC1 by real-time PCR and western blotting. (E) HCT116/Oxa cells transfected with si-NC, si-ERCC1-1, or si-ERCC1-2 were treated with increasing concentrations of Oxa for $48 \mathrm{~h}$. Data are expressed as the means $\pm \mathrm{SD}$ from three independent experiments. "P<0.05. ERCC1, excision repair cross-complementing group 1; Oxa, oxaliplatin.

parental cells. To explore which protein was responsible for Oxa resistance in HCT116/Oxa cells, western blot analysis was used. Elevated levels of ERCC1, a major protein involved in the nucleotide excision repair pathway, were observed in HCT116/Oxa cells compared with HCT116 cells (Fig. 1B). To confirm whether ERCC1 expression is involved in Oxa-resistance, the HCT116/Oxa cell sensitivity to Oxa was analyzed after ERCC1 knockdown. ERCC1 mRNA and protein expression levels were significantly suppressed by si-ERCC1 transfection in HCT116/Oxa cells (Fig. 1C and D), and ERCC1 knockdown effectively attenuated Oxa-resistance in HCT116/Oxa cells (Fig. 1E).

HCT116/Oxa cells exhibit an EMT phenotype. EMT plays a critical role in drug resistance. Morphological analysis under an inverted phase contrast microscope revealed that HCT116 cells had a round morphology, while HCT116/Oxa cells were of irregular shapes including long strips, fusiform, and polygonal (Fig. 2A). These morphological differences indicated that HCT116/Oxa cells have a mesenchymal-like phenotype as evidenced by the relative downregulation of the epithelial biomarker E-cadherin and upregulation of the mesenchymal biomarker vimentin (Fig. 2B and C). The EMT phenotype of HCT116/Oxa cells was confirmed by immunofluorescence staining (Fig. 2D). The Transwell assay revealed that HCT116/Oxa cells had a higher capacity for migration relative to HCT116 cells (Fig. 2E).

Identification of differentially expressed proteins and enrichment analysis. To gain further understanding of the molecular mechanisms involved in Oxa-resistance in HCT116/Oxa cells, TMT-based quantitative proteomic analysis was performed. A total of 5,345 proteins were identified in this study, of which 4,599 had available quantitative information. A full list of proteins and relevant MS data are presented in Supplementary Data I. Of the 4,599 commonly expressed proteins, 64 were upregulated (fold ratio $>1.5$ ) and 50 were downregulated (fold ratio <0.67) in HCT116/Oxa cells compared with HCT116 cells (a full list of proteins is presented in Supplementary Data II). The differential expression of proteins commonly expressed in parental and Oxa-resistant cell lines was further visualized using an expression-based heatmap (Fig. 3A).

To classify categories of commonly expressed proteins and canonical pathways affected by the up- or downregulation of these proteins, GO enrichment analysis was performed using DAVID and KEGG. The enrichment analysis of dysregulated proteins in cellular component, 
A

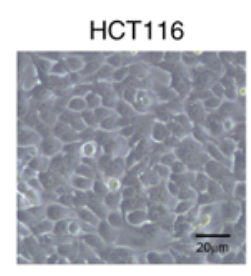
HCT116/Oxa

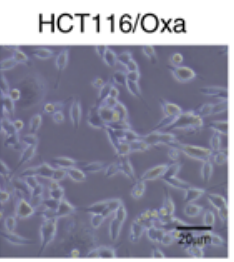

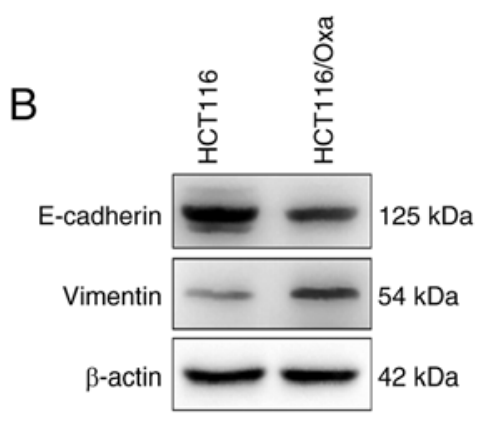

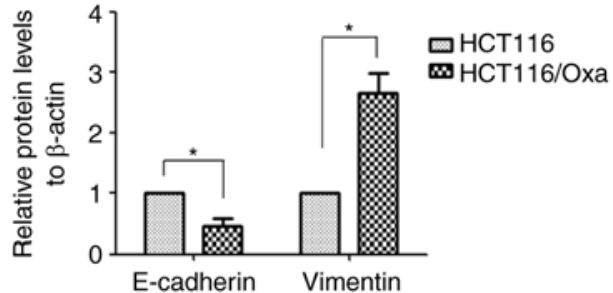

D
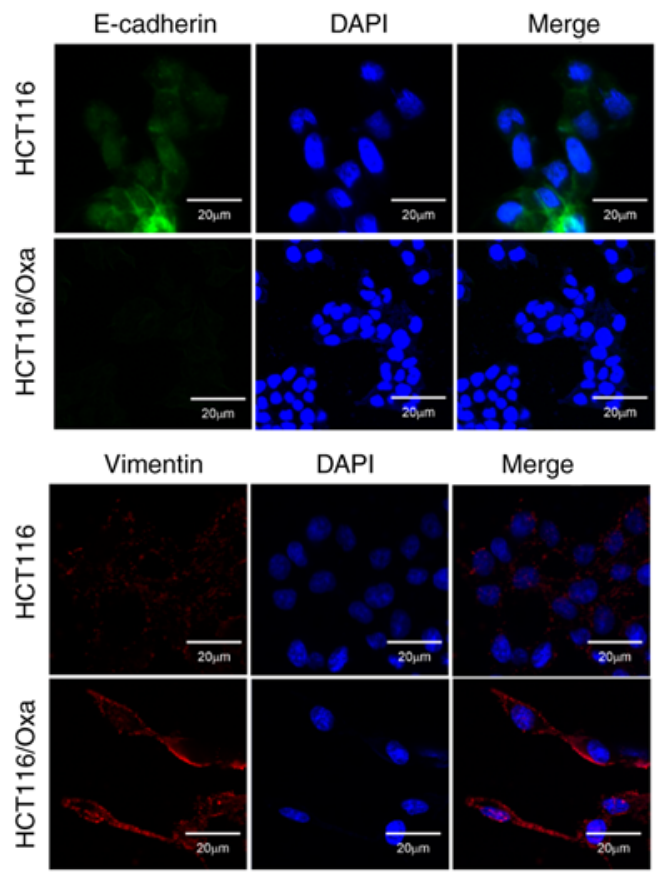
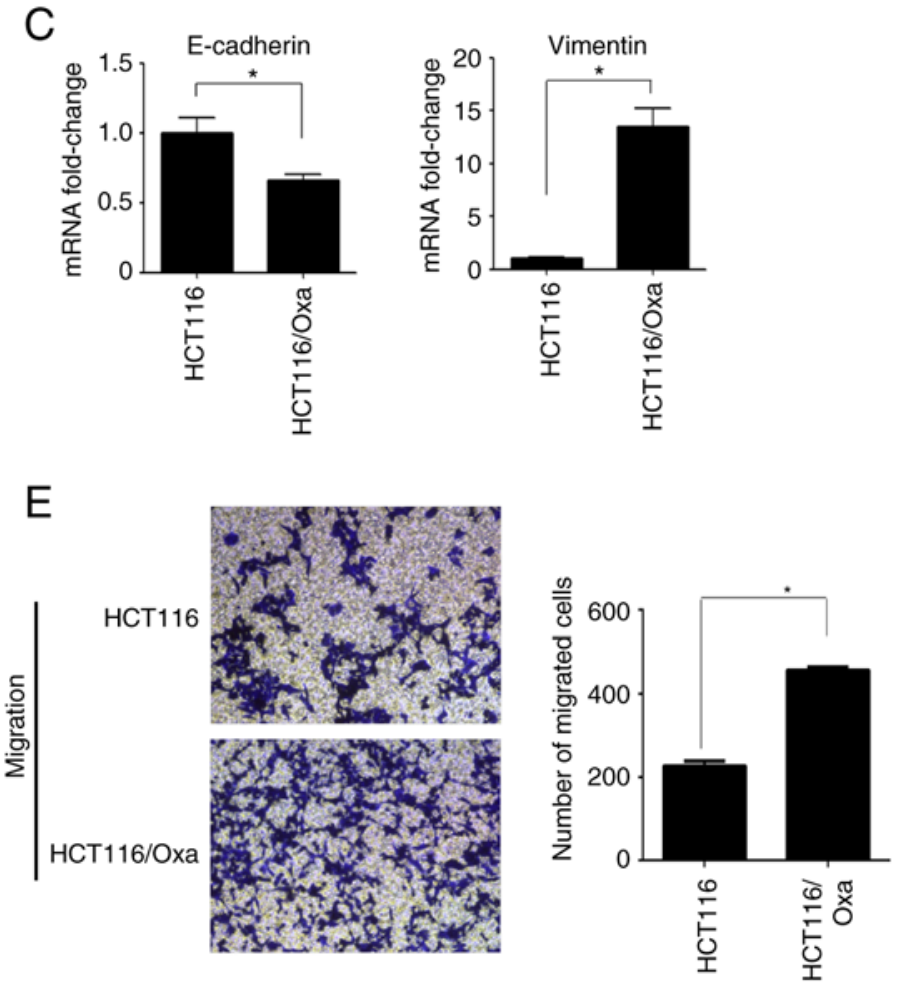

Figure 2. HCT116/Oxa cells exhibit an EMT phenotype compared with HCT116 cells. (A) Morphology of HCT116 and HCT116/Oxa cells. Scale bars, $20 \mu \mathrm{m}$. (B) The expression of E-cadherin and vimentin in HCT116 and HCT116/Oxa cells was examined by western blotting. $\beta$-actin was the loading control. (C) Quantitative real-time PCR was used to quantify E-cadherin and vimentin mRNA expression in HCT116 and HCT116/Oxa cells. (D) E-cadherin and vimentin expression was confirmed by immunofluorescence. (E) Transwell migratory assay revealed a significantly increased migratory ability of HCT116/Oxa cells compared with HCT116 cells. " $\mathrm{P}<0.05$. Oxa, oxaliplatin; EMT, epithelial-mesenchymal transition.

biological process, and molecular function is presented in Fig. 3B. In cellular component analysis, the majority of identified proteins were classified into the extracellular region, extracellular region part, extracellular space, and extracellular exosome. Molecular functional classification revealed that most of these proteins were involved in oxidoreductase activity, aldehyde dehydrogenase [NAD $\left.(\mathrm{P})^{+}\right]$ activity, oxidoreductase activity, acting on the $\mathrm{CH}-\mathrm{OH}$ group of donors, and virus receptor activity. Regarding biological processes, most of the identified proteins were enriched in small molecule metabolic processes, single organism metabolic processes, oxidation-reduction processes, and organic acid metabolic processes. KEGG analysis identified nine significant pathways $(\mathrm{P}<0.05$; Fig. $3 \mathrm{C})$, with lysosome and central carbon metabolism in cancer being the most significantly enriched. Notably, there was a good agreement of selected validation immunoblots with MS data (Fig. 3D).
DHRS2 knockdown reverses Oxa resistance through ERCC1 in HCT116/Oxa cells and inhibits OXA-induced EMT. To explore the role of DHRS2 in CRC cell Oxa-resistance, transient knockdown experiments were next performed. HCT116/Oxa cells transfected with control or DHRS2 siRNAs were treated with different concentrations of Oxa. As revealed in Fig. 4A and B, DHRS2-specific siRNA significantly reduced DHRS2 mRNA and protein expression. The CCK-8 assay revealed that the suppression of DHRS2 decreased the viability of HCT116/Oxa cells compared with cells transfected with control siRNA (Fig. 4C). Transwell assays revealed that the migration capacities of HCT116/Oxa cells were reduced in the si-DHRS2 group relative to the si-NC group (Fig. 4D).

To investigate the function(s) of DHRS2 in Oxa-resistance in HCT116/Oxa cells with an EMT phenotype, the protein expression of ERCC1 and E-cadherin was assessed. Western blotting demonstrated reduced expression of ERCC1 and 
increased expression of E-cadherin in the si-DHRS2 group compared with the si-control group (Fig. 4E). Collectively, these data revealed that DHRS2 is an important factor in Oxa resistance and EMT in CRC cells.

DHRS2 confers Oxa resistance through the p53/ERCC1 pathway. Next, the mechanism underlying the involvement of DHRS2 in Oxa-resistance in CRC cells was explored. Because DHRS2 has been reported to stabilize p53 in an osteosarcoma cell line (25), it was examined whether it was also stabilized in HCT116/Oxa cells. Our previous results revealed that DHRS2 and p53 were markedly increased in HCT116/Oxa cells compared with the parental cell line. Silencing of DHRS2 in HCT116/Oxa cells by siRNA decreased p53 compared with control cells (Fig. 5A). To assess whether p53 regulates ERCC1 expression, p53 siRNA was used and the results revealed a significant decrease of ERCC1 protein expression (Fig. 5B).

\section{Discussion}

Although recent chemotherapy regimens have significantly improved the survival of patients with metastatic disease, almost all patients with CRC eventually become chemo-resistant with distant metastases $(26,27)$. Therefore, it is critical to delineate drug resistance mechanisms to commonly used therapeutic agents such as Oxa to improve CRC patient survival.

CRC cells develop resistance to Oxa through a reduction of cellular accumulation, intracellular inactivation, blocking the induction of apoptosis, and the enhancement of DNA repair. ERCC1 is an important mediator of nucleotide excision repair (NER), and is widely recognized as a powerful component of the DNA repair mechanism (28). Previous studies have revealed that ERCC1 expression levels are positively correlated with the DNA repair capacity, and are associated with cellular and clinical resistance to platinum-based therapy of lung, ovarian, and gastric cancer $(6,29,30)$. Furthermore, several prospective validation studies revealed that ERCC1 expression may serve as a biomarker for platinum-based therapy responses (31-33). In the present study, the Oxa-resistant human CRC cell line HCT116/Oxa was successfully established. It was revealed that of several selected drug resistance-associated proteins, the expression of ERCC1 was the most elevated in these cells, and that reducing ERCC1 expression resulted in loss of the chemo-resistant phenotype. These results suggested that the aberrant expression of ERCC1 may be a major cause of chemotherapy resistance in HCT116/Oxa cells.

To further explore the mechanisms of Oxa-resistance in HCT116/Oxa cells, we searched for proteins associated with drug resistance in parental HCT116 cells and HCT116/Oxa cells using TMT-based quantitative proteomics. DHRS2 expression was the most significantly upregulated in HCT116/Oxa cells, and this was confirmed by western blotting. Moreover, knockdown of DHRS2 in HCT116/Oxa cells resulted in an enhancement of Oxa-sensitivity, while DHRS2 silencing suppressed ERCC1 expression. These results indicated that DHRS2 facilitates HCT116/Oxa cell chemotherapy sensitivity to Oxa by promoting the expression of ERCC1.

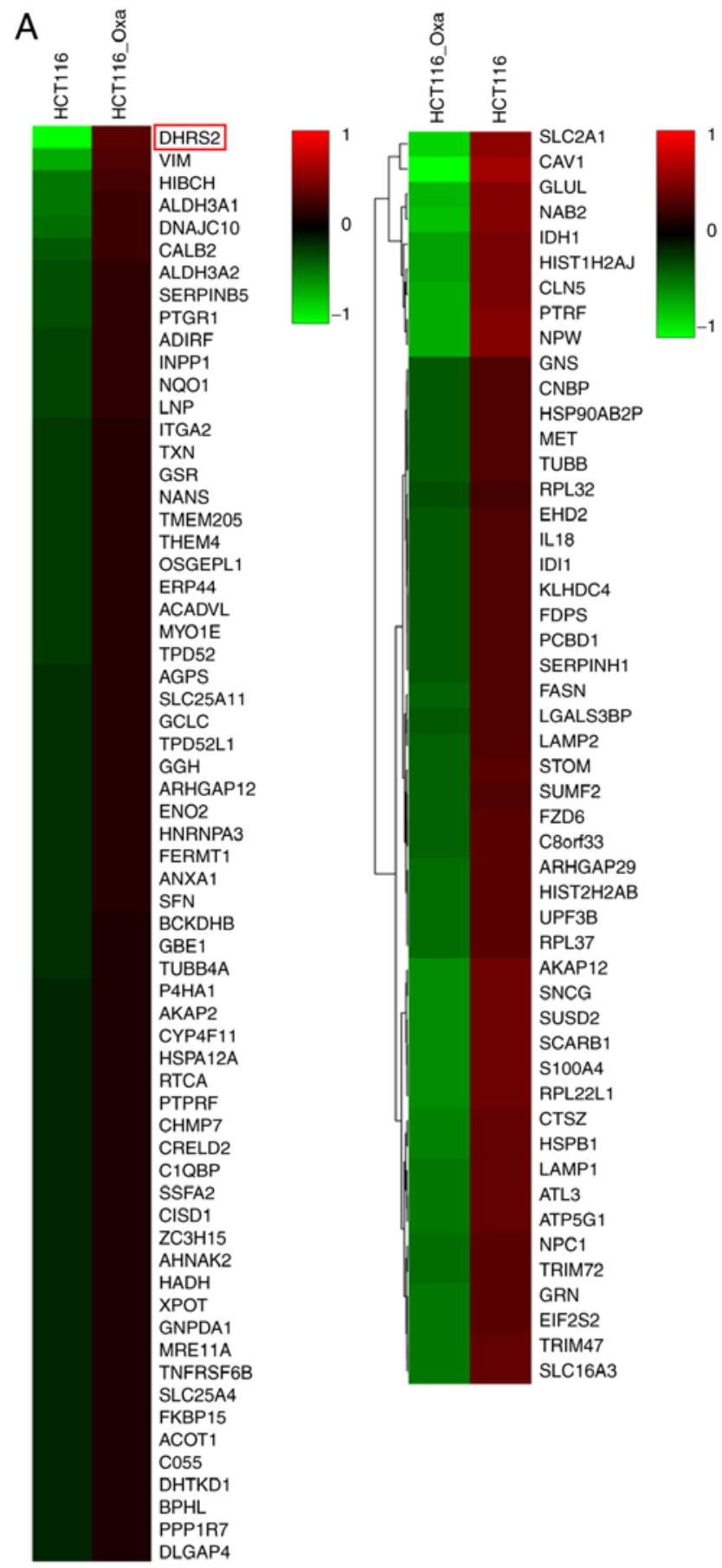

Figure 3. Bioinformatics analysis of proteins and pathways. (A) Heatmap of the expression levels of 114 dysregulated proteins. Increased and decreased proteins are represented by a range of red and green intensities, respectively.

DHRS2 was previously reported to bind to mouse double minute 2 homolog (MDM2), resulting in the attenuation of MDM2-mediated p53 degradation (25). Consistent with this, in the present study it was revealed that p53 was decreased in si-DHRS2 HCT116/Oxa cells and was increased in DHRS2-overexpressing HCT116/Oxa cells compared with HCT116 cells. p53 is one of the most well-studied tumor suppressor genes. It could be activated through a myriad of cellular stresses ranging from DNA damage to hypoxia, stress, and a plethora of other causes. Upon activation, p53 acts as a zinc-containing transcription factor that regulates 

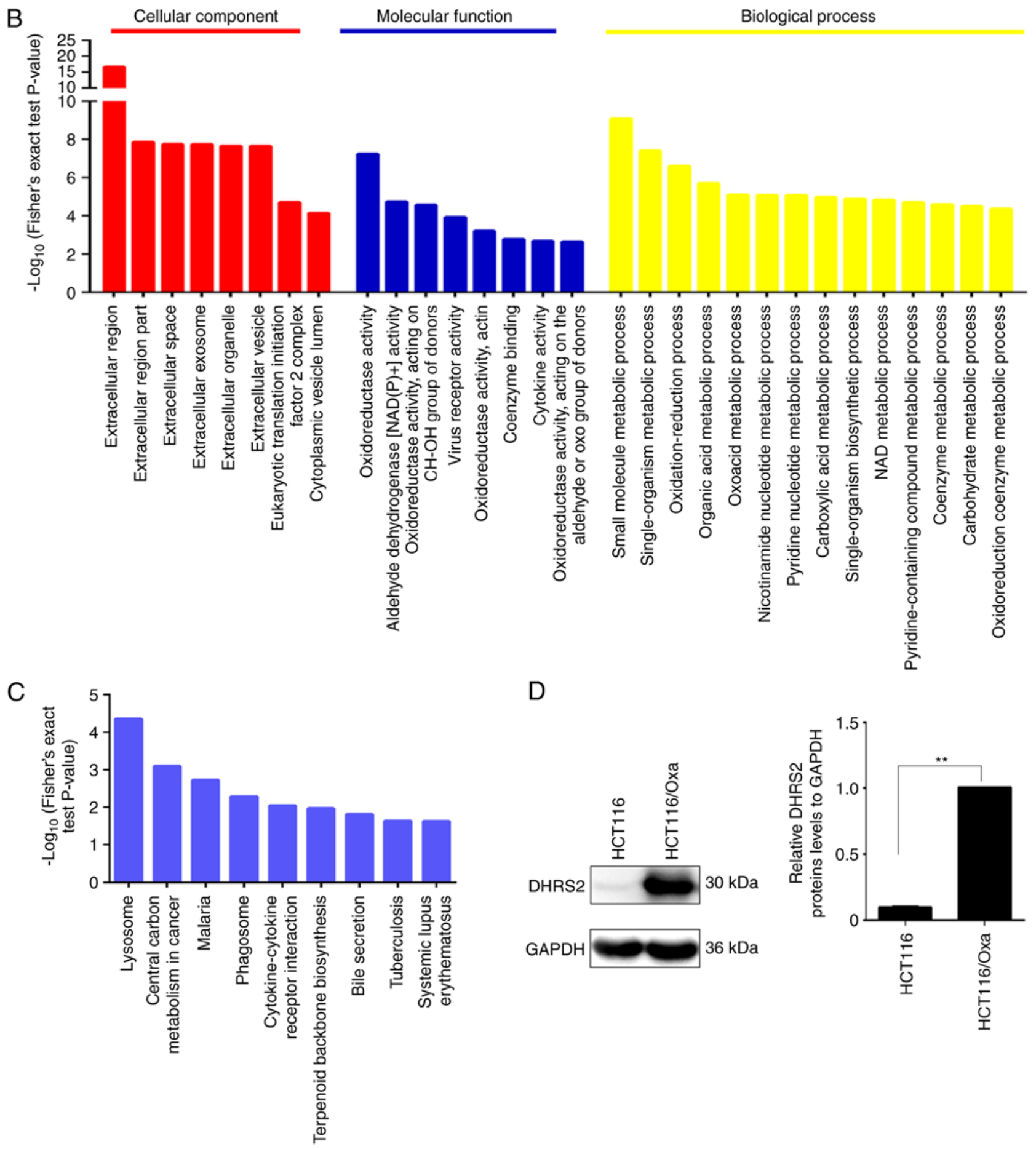

D
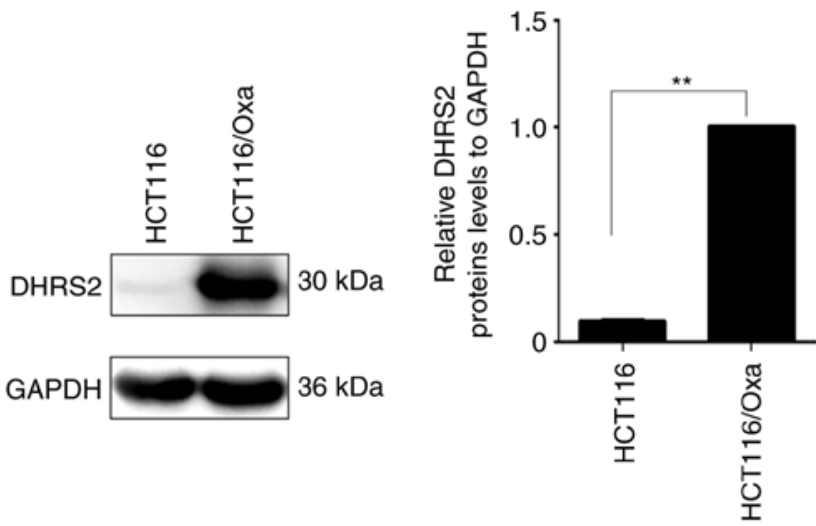

Figure 3. Continued. (B) GO enrichment analysis of dysregulated proteins involved in cell components, molecular functions, and biological processes. (C) Distribution of enriched KEGG pathways. (D) Validation of DHRS2 expression in HCT116 and HCT116/Oxa cells. ** P<0.01. GO, Gene Ontology; KEGG, Kyoto Encyclopedia of of Genes and Genomes; DHRS2, dehydrogenase/reductase SDR family member 2; Oxa, oxaliplatin.

downstream genes, including p21 which leads to cell cycle arrest, as well as PUMA/FAS/BAX which induce apoptosis (34). Previous studies have demonstrated that p53 also modulates cisplatin sensitivity and the NER pathway in response to cisplatin-induced DNA damage. Liu et al (35) reported that p53 directly bound the ERCC1 promoter and induced gene expression, which protected cells from cisplatin-induced DNA damage. In the present study, p53 silencing in HCT116/Oxa cells significantly reduced ERCC1 expression, indicating that the Oxa-induced DNA damage function of DHRS2 occurs via stabilization of p53 and upregulation of ERCC1.

Recent studies have revealed that EMT is a vital process that modulates cancer progression and metastasis. Moreover, accumulating evidence implicates EMT in drug resistance (36), while some cultured resistant cells expressing aggressive phenotypes have the EMT phenotype (37). Similarly, in the present study, it was demonstrated that HCT116/Oxa cells displayed an EMT phenotype, with decreased E-cadherin and increased vimentin expression, and 


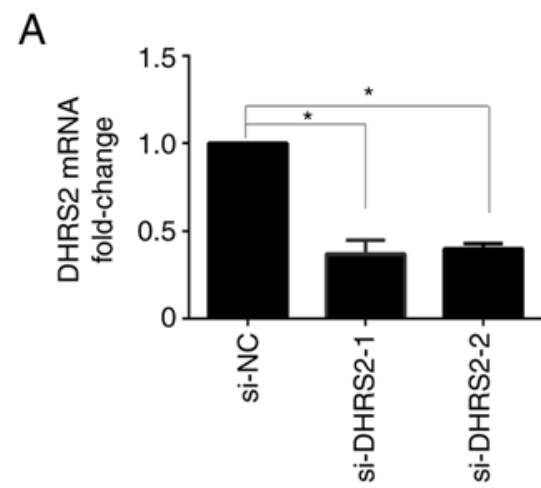

C
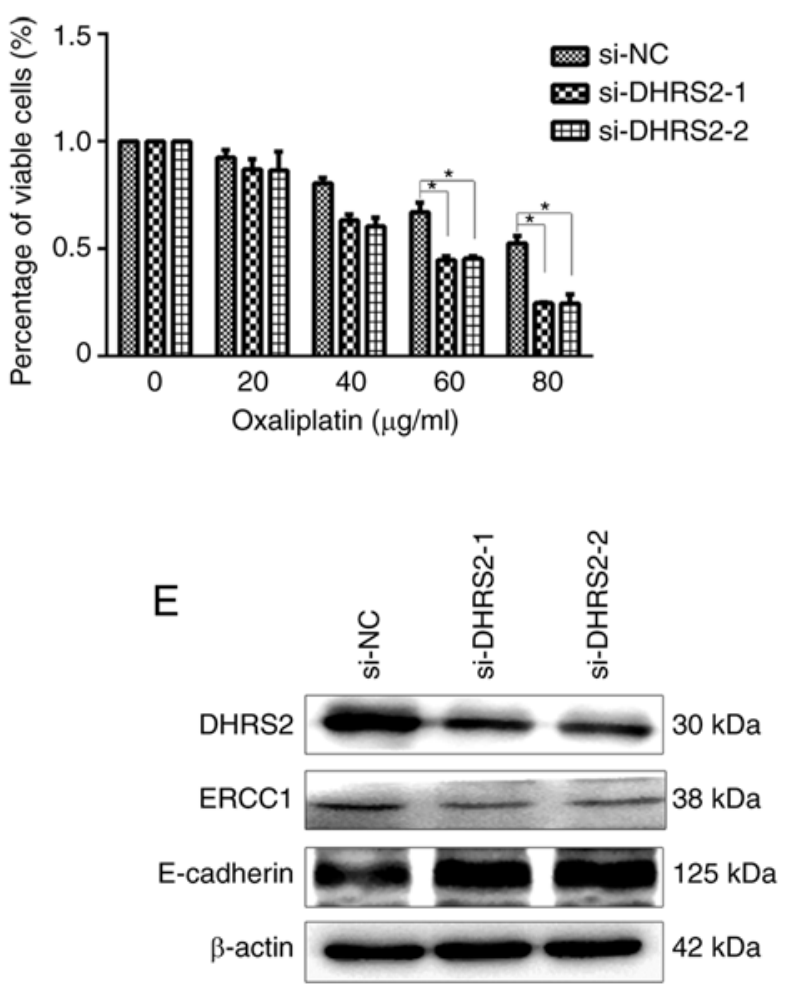

B
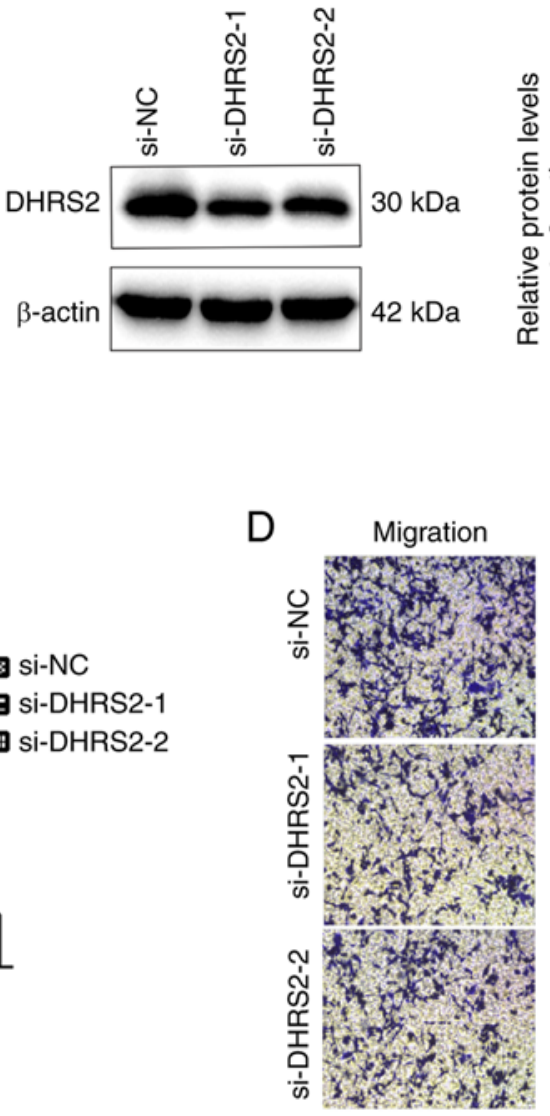
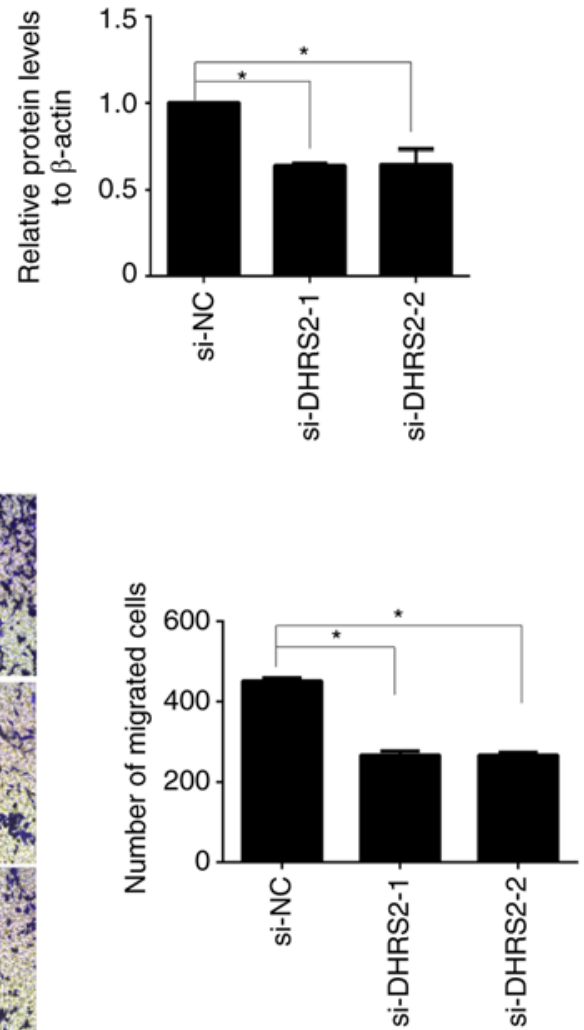

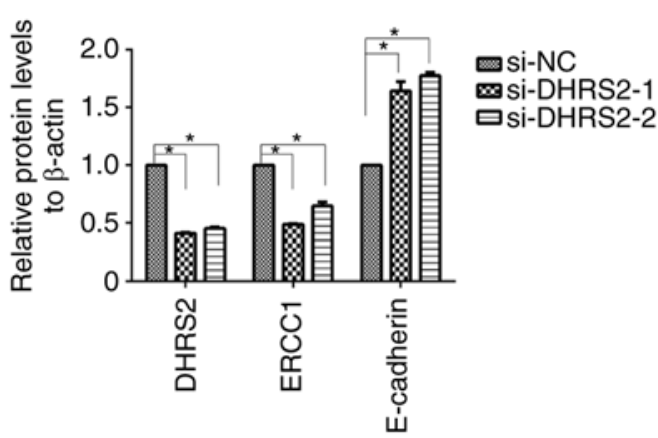

Figure 4. DHRS2 downregulates ERCC1 expression and decreases cell sensitivity to Oxa. (A) DHRS2 was effectively silenced at the mRNA level by siRNA as revealed by quantitative real-time PCR. (B) DHRS2 was effectively silenced at the protein level by siRNA as revealed by western blot analysis. (C) CCK-8 assays identifying the role of DHRS2 in HCT116/Oxa cells. (D) Transwell assays revealed that si-DHRS2 inhibited the migration of HCT116/Oxa cells. (E) HCT116/Oxa cells were transfected with si-NC or si-DHRS2 for $48 \mathrm{~h}$, and then the expression of DHRS2, ERCC1, and E-cadherin was examined by western blotting. "P<0.05. DHRS2, dehydrogenase/reductase SDR family member 2; ERCC1, excision repair cross-complementing group 1; Oxa, oxaliplatin.

enhanced migratory capacity. Further analyses observed the opposite effects following the silencing of DHRS2. Recently, it was reported that DHRS2 inhibits cell growth and motility in ESCC (38). Additionally, the overexpression of miR-145-3p significantly reduced ESCC cancer cell proliferation, migration, and invasive abilities by silencing DHRS2 (21). A set of transcriptional factors have been implicated in the regulation of EMT, including Snail, Slug, ZEB1, and Twist (39). Among them, Snail and Slug are degraded by ubiquitination via the proteasome pathway resulting in E-cadherin expression $(40,41)$. It has been revealed that MDM2, one of the E3 ligases of p53, reduces lung cancer mobility and metastasis through mediation of Slug degradation via the ubiquitination proteasome pathway $(41,42)$. Accordingly, it was speculated that DHRS2 expression may prompt the migration of CRC cells by interacting with E3 ubiquitin ligase MDM2 and interfere with its function which suppresses degradation of EMT-inducing transcriptional factor Slug/Snail. Further experiments are required to elucidate the exact mechanism of DHRS2 in the regulation of the EMT process in cancer cells.

In conclusion, it was revealed that HCT116/Oxa cells acquire EMT features and demonstrate increased migration compared with parental HCT116 cells. It was also revealed that DHRS2 regulated ERCC1 to promote chemotherapy resistance through a p53-dependent pathway, and mediated EMT by suppressing E-cadherin expression. The present study identifies DHRS2 as 

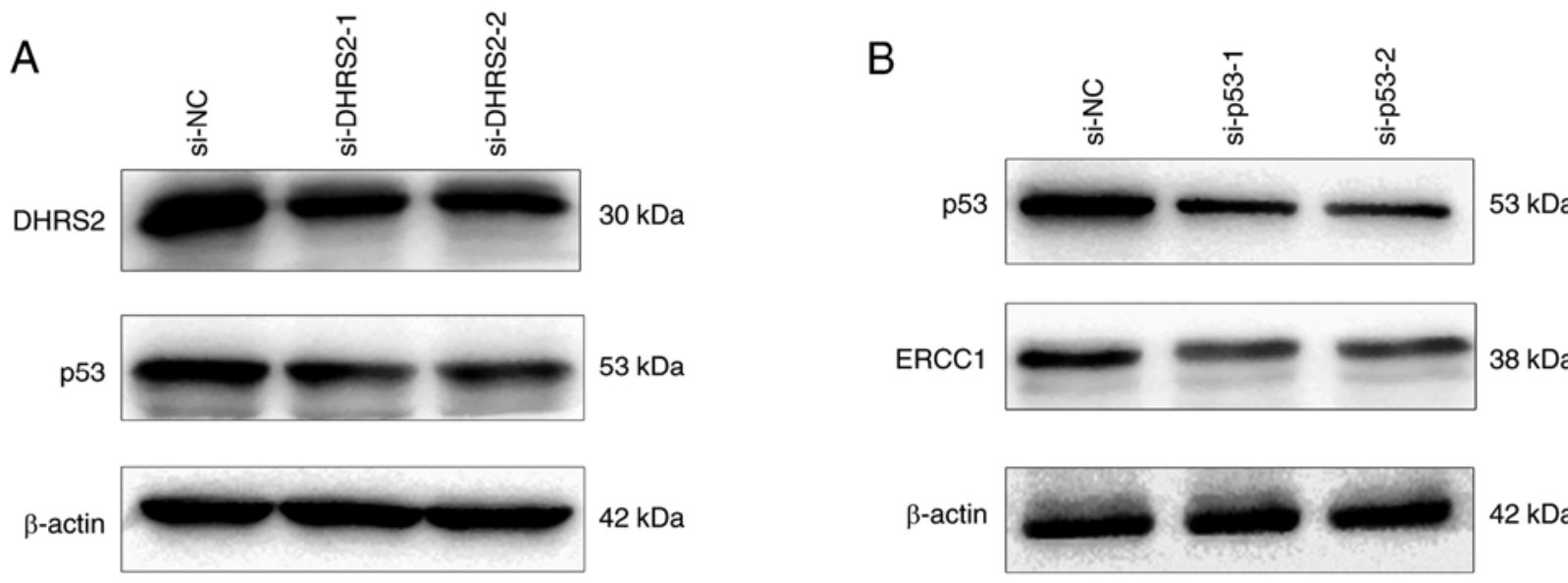

$53 \mathrm{kDa}$
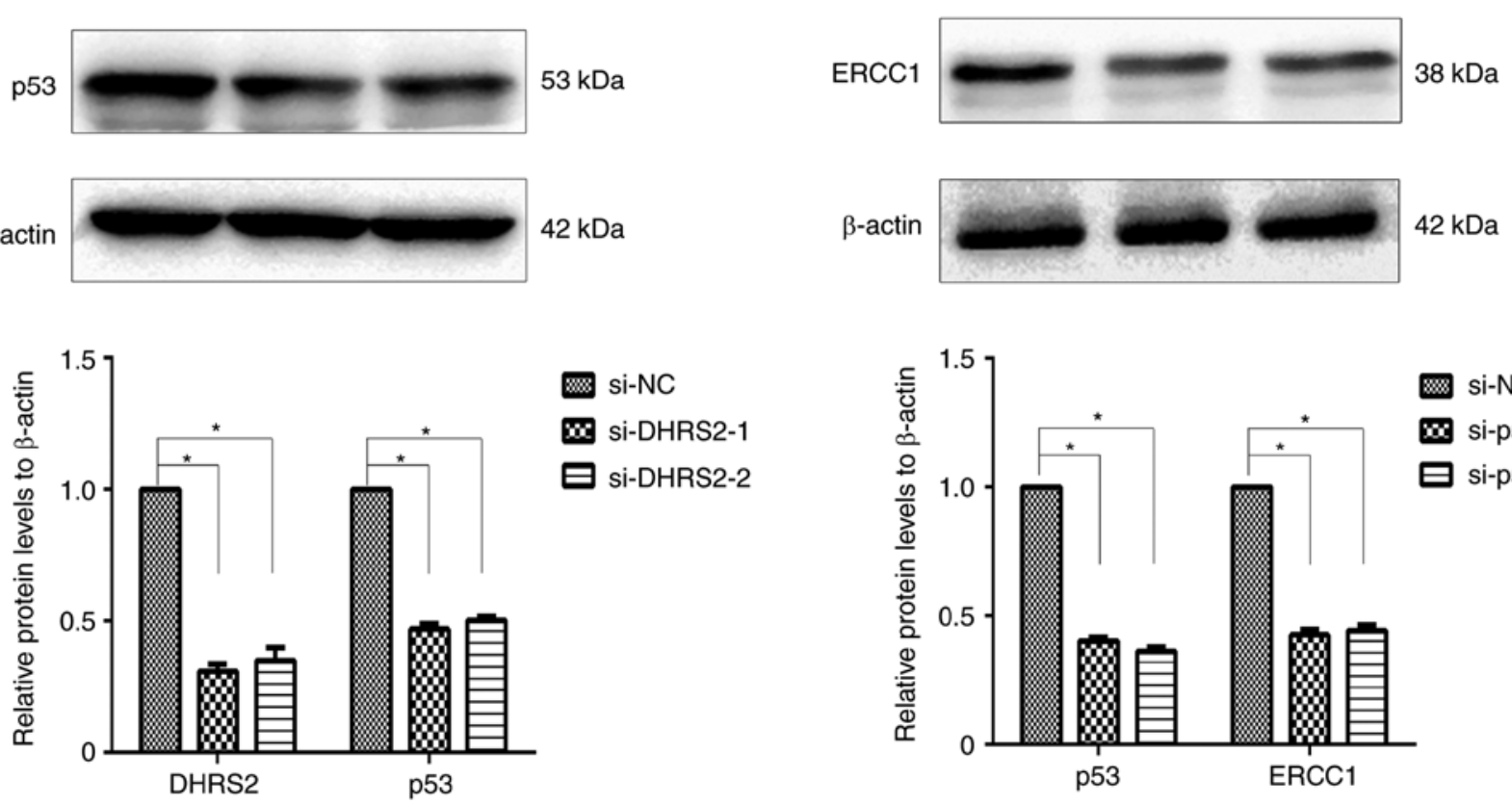

Figure 5. DHRS2 downregulates ERCC1 in a p53-dependent manner. (A) The effect of DHRS2 knockdown on the expression of p53 protein. (B) The effect of p53 knockdown on the expression of ERCC1 protein. ${ }^{\mathrm{P}}<0.05$. DHRS2, dehydrogenase/reductase SDR family member 2; ERCC1, excision repair cross-complementing group 1; Oxa, oxaliplatin.

a potential CRC therapeutic target for simultaneous addressing of cancer metastasis and chemoresistance.

\section{Acknowledgements}

Not applicable.

\section{Funding}

The present study was funded by the National Natural Science Foundation of China (grant no. 81502599), the Key Research and Development Projects in Anhui province (grant no. 201904a07020082) and the Natural Science Foundation of Anhui Province (grant nos. 1608085MH229 and 1608085QH217).

\section{Availability of data and materials}

The datasets used and/or analyzed during the present study are available from the corresponding author on reasonable request.

\section{Authors' contributions}

YQL and HW conceived and designed the experiments. JML, LZ, FY and WQY performed the experiments. JML and GMJ analyzed the data and wrote the paper. YQ and HW revised the paper. All authors read and approved the final manuscript and agree to be accountable for all aspects of the research in ensuring that the accuracy or integrity of any part of the work are appropriately investigated and resolved.

\section{Ethics approval and consent to participate}

Not applicable.

\section{Patient consent for publication}

Not applicable.

\section{Competing interests}

The authors declare that they have no competing interests.

\section{References}

1. Saika K and Sobue T: Cancer statistics in the world. Gan To Kagaku Ryoho 40: 2475-2480, 2013 (In Japanese).

2. Arredondo J, Baixauli J, Pastor C, Chopitea A, Sola JJ, González I, A-Cienfuegos J, Martínez P, Rodriguez J and Hernández-Lizoain JL: Mid-term oncologic outcome of a novel approach for locally advanced colon cancer with neoadjuvant chemotherapy and surgery. Clin Transl Oncol 19: 379-385, 2017.

3. Holohan C, Van Schaeybroeck S, Longley DB and Johnston PG Cancer drug resistance: An evolving paradigm. Nat Rev Cancer 13: 714-726, 2013 
4. Brabletz T, Kalluri R, Nieto MA and Weinberg RA: EMT in cancer. Nat Rev Cancer 18: 128-134, 2018.

5. Thiery JP, Acloque $\mathrm{H}$, Huang RY and Nieto MA: Epithelial-mesenchymal transitions in development and disease. Cell 139: 871-890, 2009.

6. Olaussen KA, Dunant A, Fouret P, Brambilla E, André F, Haddad V, Taranchon E, Filipits M, Pirker R, Popper HH, et al: DNA repair by ERCC1 in non-small-cell lung cancer and cisplatin-based adjuvant chemotherapy. N Engl J Med 355: 983-991, 2006.

7. Wang J, Chen Y, Xiang F, Li M,Li H, Chi J and Ren K: Suppression of TGF- $\beta 1$ enhances chemosensitivity of cisplatin-resistant lung cancer cells through the inhibition of drug-resistant proteins. Artif Cells Nanomed Biotechnol 46: 1505-1512, 2018.

8. Wu Y, Jin D, Wang X, Du J, Di W, An J, Shao C and Guo J: UBE2C induces cisplatin resistance via ZEB1/2-dependent upregulation of ABCG2 and ERCC1 in NSCLC cells. J Oncol 2019: 8607859, 2019.

9. Hsu DS, Lan HY, Huang CH, Tai SK, Chang SY, Tsai TL, Chang CC, Tzeng CH, Wu KJ, Kao JY and Yang MH: Regulation of excision repair cross-complementation group 1 by Snail contributes to cisplatin resistance in head and neck cancer. Clin Cancer Res 16: 4561-4571, 2010

10. He S, Carman CV, Lee JH, Lan B, Koehler S, Atia L, Park CY, Kim JH, Mitchel JA, Park JA, et al: The tumor suppressor p53 can promote collective cellular migration. PLoS One 14: e0202065, 2019.

11. Donadel G, Garzelli C, Frank R and Gabrielli F: Identification of a novel nuclear protein synthesized in growth-arrested human hepatoblastoma HepG2 cells. Eur J Biochem 195: 723-729, 1991.

12. Gabrielli F and Tofanelli S: Molecular and functional evolution of human DHRS2 and DHRS4 duplicated genes. Gene 511: 461-469, 2012.

13. Bray JE, Marsden BD and Oppermann U: The human short-chain dehydrogenase/reductase (SDR) superfamily: A bioinformatics summary. Chem Biol Interact 178: 99-109, 2009.

14. Bjorkqvist AM, Wolf M, Nordling S, Tammilehto L, Knuuttila A, Kere J, Mattson K and Knuutila S: Deletions at 14q in malignant mesothelioma detected by microsatellite marker analysis. $\mathrm{Br}$ J Cancer 81: 1111-1115, 1999.

15. Debiec-Rychter M, Sciot R, Pauwels P, Schoenmakers E, Dal Cin P and Hagemeijer A: Molecular cytogenetic definition of three distinct chromosome arm $14 \mathrm{q}$ deletion intervals in gastrointestinal stromal tumors. Genes Chromosomes Cancer 32 26-32, 2001

16. Shao JY, Huang XM, Yu XJ, Huang LX, Wu QL, Xia JC, Wang HY, Feng QS, Ren ZF, Ernberg I, et al: Loss of heterozygosity and its correlation with clinical outcome and Epstein-Barr virus infection in nasopharyngeal carcinoma. Anticancer Res 21 : 3021-3029, 2001.

17. Pellegrini S, Censini S, Guidotti S, Iacopetti P, Rocchi M, Bianchi M, Covacci A and Gabrielli F: A human short-chain dehydrogenase/reductase gene: Structure, chromosomal localization, tissue expression and subcellular localization of its product. Biochim Biophys Acta 1574: 215-222, 2002.

18. Peterson LE, Ozen M, Erdem H, Amini A, Gomez L, Nelson CC and Ittmann M: Artificial neural network analysis of DNA microarray-based prostate cancer recurrence. Proceedings of the IEEE Symposium on Computational Intelligence in Bioinformatics and Computational Biology, pp1-8, 2005.

19. Shedden KA, Taylor JM, Giordano TJ, Kuick R, Misek DE Rennert G, Schwartz DR, Gruber SB, Logsdon C, Simeone D, et al: Accurate molecular classification of human cancers based on gene expression using a simple classifier with a pathological tree-based framework. Am J Pathol 163: 1985-1995, 2003.

20. Bhattacharyya C, Grate LR, Rizki A, Radisky D, Molina FJ, Jordan MI, Bissell MJ and Mian IS: Simultaneous classification and relevant feature identification in high-dimensional spaces: Application to molecular profiling data. Signal Processing 83: 729-743, 2003.

21. Shimonosono M, Idichi T, Seki N, Yamada Y, Arai T, Arigami T, Sasaki K, Omoto I, Uchikado Y, Kita Y, et al: Molecular pathogenesis of esophageal squamous cell carcinoma: Identification of the antitumor effects of miR145-3p on gene regulation. Int J Oncol 54: 673-688, 2019.

22. Yamada H, Arakawa Y, Saito S, Agawa M, Kano Y and Horiguchi-Yamada J: Depsipeptide-resistant KU812 cells show reversible P-glycoprotein expression, hyper-acetylated histones, and modulated gene expression profile. Leukemia research 30 : 723-734, 2006
23. Han Y, Song C, Wang J, Tang H, Peng Z and Lu S: HOXA13 contributes to gastric carcinogenesis through DHRS2 interacting with MDM2 and confers 5-FU resistance by a p53-dependent pathway. Mol Carcinog 57: 722-734, 2018.

24. Livak KJ and Schmittgen TD: Analysis of relative gene expression data using real-time quantitative PCR and the 2(-Delta Delta C(T)) method. Methods 25: 402-408, 2001

25. Deisenroth $\mathrm{C}$, Thorner AR, Enomoto T, Perou CM and Zhang $\mathrm{Y}$ Mitochondrial Hep27 is a c-Myb target gene that inhibits Mdm2 and stabilizes p53. Mol Cell Biol 30: 3981-3993, 2010.

26. Cunningham D, Atkin W, Lenz HJ, Lynch HT, Minsky B, Nordlinger B and Starling N: Colorectal cancer. Lancet 375: 1030-1047, 2010

27. Siegel R, Ma J, Zou Z and Jemal A: Cancer statistics, 2014. CA Cancer J Clin 64: 9-29, 2014

28. Bowden NA: Nucleotide excision repair: Why is it not used to predict response to platinum-based chemotherapy? Cancer Lett 346: 163-171, 2014.

29. Park DJ and Lenz HJ: Determinants of chemosensitivity in gastric cancer. Curr Opin Pharmacol 6: 337-344, 2006.

30. Selvakumaran M, Pisarcik DA, Bao R, Yeung AT and Hamilton TC: Enhanced cisplatin cytotoxicity by disturbing the nucleotide excision repair pathway in ovarian cancer cell lines. Cancer Res 63: 1311-1316, 2003.

31. Reynolds C, Obasaju C, Schell MJ, Li X, Zheng Z, Boulware D, Caton JR, Demarco LC, O'Rourke MA, Shaw Wright G, et al: Randomized phase III trial of gemcitabine-based chemotherapy with in situ RRM1 and ERCC1 protein levels for response prediction in non-small-cell lung cancer. J Clin Oncol 27: 5808-5815, 2009.

32. Cobo M, Isla D, Massuti B, Montes A, Sanchez JM, Provencio M, Viñolas N, Paz-Ares L, Lopez-Vivanco G, Muñoz MA, et al: Customizing cisplatin based on quantitative excision repair cross-complementing $1 \mathrm{mRNA}$ expression: A phase III trial in non-small-cell lung cancer. J Clin Oncol 25: 2747-2754, 2007.

33. Simon G, Sharma A, Li X, Hazelton T, Walsh F, Chiappori CA, Haur E, Tanvetyanon T, Antonia S, Cantor A and Bepler G: Feasibility and efficacy of molecular analysis-directed individualized therapy in advanced non-small-cell lung cancer. J Clin Oncol 25: 2741-2746, 2007

34. Kruiswijk F, Labuschagne CF and Vousden KH: p53 in survival, death and metabolic health: A lifeguard with a licence to kill. Nat Rev Mol Cell Biol 16: 393-405, 2015.

35. Liu YC, Chang PY and Chao CC: CITED2 silencing sensitizes cancer cells to cisplatin by inhibiting p53 trans-activation and chromatin relaxation on the ERCC1 DNA repair gene. Nucleic Acids Res 43: 10760-10781, 2015.

36. Wang H, Zhang G, Zhang H, Zhang F, Zhou B, Ning F, Wang HS Cai SH and Du J: Acquisition of epithelial-mesenchymal transition phenotype and cancer stem cell-like properties in cisplatin-resistant lung cancer cells through AKT/ $\beta$-catenin/Snail signaling pathway. Eur J Pharmacol 723: 156-166, 2014.

37. Yang AD, Fan F, Camp ER, van Buren G, Liu W, Somcio R, Gray MJ, Cheng H, Hoff PM and Ellis LM: Chronic oxaliplatin resistance induces epithelial-to-mesenchymal transition in colorectal cancer cell lines. Clin Cancer Res 12: 4147-4153, 2006.

38. Zhou Y, Wang L, Ban X, Zeng T, Zhu Y, Li M, Guan XY and Li Y: DHRS2 inhibits cell growth and motility in esophageal squamous cell carcinoma. Oncogene 37: 1086-1094, 2018

39. Quail DF and Joyce JA: Microenvironmental regulation of tumor progression and metastasis. Nat Med 19: 1423-1437, 2013.

40. Zhou BP, Deng J, Xia W, Xu J, Li YM, Gunduz M and Hung MC: Dual regulation of Snail by GSK-3beta-mediated phosphorylation in control of epithelial-mesenchymal transition. Nat Cell Biol 6: 931-940, 2004

41. Wang SP, Wang WL, Chang YL, Wu CT, Chao YC, Kao SH, Yuan A, Lin CW, Yang SC, Chan WK, et al: p53 controls cancer cell invasion by inducing the MDM2-mediated degradation of Slug. Nat Cell Biol 11: 694-704, 2009

42. Lin TY and Hsu HY: Ling Zhi-8 reduces lung cancer mobility and metastasis through disruption of focal adhesion and induction of MDM2-mediated Slug degradation. Cancer Lett 375 340-348, 2016.

This work is licensed under a Creative Commons Attribution-NonCommercial-NoDerivatives 4.0 International (CC BY-NC-ND 4.0) License. 